\title{
O FUTURO DA ESCOLA E AS TECNOLOGIAS: ALGUNS ASPECTOS À LUZ DO DIÁLOGO ENTRE PAULO FREIRE E SEYMOUR PAPERT
}

\author{
EL FUTURO DE LA ESCUELA Y LAS TECNOLOGÍAS: ALGUNOS ASPECTOS A \\ LA LUZ DEL DIÁLOGO ENTRE PAULO FREIRE Y SEYMOUR PAPERT
}
THE FUTURE OF SCHOOL AND TECHNOLOGIES: SOME ASPECTS IN THE LIGHT OF THE DIALOGUE BETWEEN PAULO FREIRE AND SEYMOUR PAPERT

\author{
Rosane Michelli de CASTRO ${ }^{1}$ \\ Lucirene Andrea Catini LANZI ${ }^{2}$
}

RESUMO: Apresentamos neste artigo resultados de reflexões sobre a escola, aspectos da sua história e atualidade, bem como suas perspectivas no âmbito da sociedade capitalista, marcada por desigualdades sócio-econômicas, à luz do diálogo entre os educadores brasileiro e sul-africano, Paulo Freire e Seymour Pappert, respectivamente, no vídeo intitulado "Seymour Papert e Paulo Freire: uma conversa sobre informática, ensino e aprendizagem", sobre o futuro da escola e o papel das tecnologias. Tais reflexões originaram-se das nossas atividades desenvolvidas em curso de Pedagogia de uma universidade pública paulista, centralmente na disciplina de Didática I, cujas preocupações fixam-se em torno de duas questões fundamentais que refletem sobre a formação e o trabalho do professor, a importância de conceituar e de situar a educação e o ensino não apenas em função de seus fins, mas também enfatizando sua função política e sua especificidade e, atrelando a essa questão, a necessidade das apropriações teóricas que embasam as teorias pedagógicas e decorrentes didáticas, e de onde derivam os diferentes métodos e técnicas de ensino, dentre os quais aqueles desenvolvidos por meio das tecnologias. Como resultados das nossas reflexões tem-se que a função política e especificidade da educação e do ensino, quando recuperadas pelo professor, mediante fundamentos educacionais centrados na ideia de educação e ensino para todos, e potencializada com a utilização da tecnologia e suas ferramentas, fortalece a importância da escola que se deseja ser espaço e tempo para que atividades teóricas e sociais sejam realizadas pelos sujeitos em constante processo de desenvolvimento.

PALAVRAS-CHAVE: Educação. Tecnologias e suas ferramentas. Especificidade e função política da educação e do ensino. Importância da escola. Desenvolvimento humano.

1 Universidade Estadual Paulista (Unesp), Marília - SP - Brasil. Professora Doutora junto ao Departamento de Didática e ao Programa de Pós-Graduação em Educação. E-mail: rosanemichelli@marilia.unesp.br.

${ }^{2}$ Professora junto à Escola Técnica "Paulo Guerreiro Franco" - Etec Vera Cruz - SP - Brasil. Doutorado em Educação - PPGE - ambos da Faculdade de Filosofia e Ciências - FFC-UNESP/Marília-SP. E-mail: lu_lanzi@hotmail.com. 
RESUMEN: En este artículo se presentan resultados de reflexiones sobre la escuela, aspectos de su historia y actualidad, así como sus perspectivas en el ámbito de la sociedad capitalista, marcada por desigualdades socioeconómicas, a la luz del diálogo entre los educadores brasileño y sudafricano, Paulo Freire y, Seymour Pappert, respectivamente, en el vídeo titulado "Seymour Papert y Paulo Freire: una conversación sobre informática, enseñanza y aprendizaje", sobre el futuro de la escuela y el papel de las tecnologías. Tales reflexiones se originaron de nuestras actividades desarrolladas en curso de Pedagogía de una universidad pública paulista, centralmente en la disciplina de Didáctica I, cuyas preocupaciones se fijan en torno a dos cuestiones fundamentales que se reflejan sobre la formación y el trabajo del profesor, La importancia de conceptualizar y de situar la educación y la enseñanza no sólo en función de sus fines, sino también enfatizando su función política y su especificidad y, atreviendo a esa cuestión, la necesidad de las apropiaciones teóricas que fundamentan las teorías pedagógicas y derivadas didácticas, y De donde derivan los diferentes métodos y técnicas de enseñanza, entre las cuales aquellas desarrolladas por medio de las tecnologías. Como resultados de nuestras reflexiones se tiene que la función política y la especificidad de la educación y la enseñanza, cuando son recuperadas por el profesor, mediante fundamentos educativos centrados en la idea de educación y enseñanza para todos, y potenciada con la utilización de la tecnología y sus herramientas, fortalece La importancia de la escuela que se desea ser espacio y tiempo para que las actividades teóricas y sociales sean realizadas por los sujetos en constante proceso de desarrollo.

PALAVRAS CLAVE: Educación. Tecnologías y sus herramientas. Especificidad y función política de la educación y del aprendizaje. Importância de la escuela. Desarrollo humano.

ABSTRACT: We present in this article results of reflections on the school, aspects of its history and actuality, as well as its perspectives within the capitalist society, marked by socioeconomic inequalities, in the light of the dialogue between Brazilian and South African educators, Paulo Freire and Seymour Pappert, respectively, in the video entitled "Seymour Papert and Paulo Freire: a conversation about computing, teaching and learning", about the future of the school and the role of technologies. These reflections originated from our activities developed in the course of Pedagogy of a public university of São Paulo, centrally in the discipline of Didactic I, whose concerns are fixed around two fundamental questions that are reflected on the formation and the work of the teacher, the Importance of conceptualizing and situating education and teaching not only in function of its aims, but also emphasizing its political function and its specificity and, attaching to this question, the necessity of the theoretical appropriations that underlie pedagogical and didactic theories, and From which derive the different methods and techniques of teaching, among which those developed through the technologies. As a result of our reflections, the political function and specificity of education and teaching, when recovered by the teacher, through educational foundations centered on the idea of education and teaching for all, and enhanced by the use of technology and its tools, strengthens The importance of the school that wants to be space and time for theoretical and social activities to be performed by the subjects in a constant process of development. 
KEYWORDS: Education. Technologies and their tools. Specificity and political function of education and teaching. Importance of school. Human development.

\section{Introdução}

Em nossas atividades de docência, ensino e extensão desenvolvidas em uma universidade pública brasileira do estado de São Paulo, centralmente no curso de Pedagogia, na disciplina de Didática I, nossas preocupações fixam-se em torno de duas questões fundamentais que se refletem sobre a formação e o trabalho do professor: a importância de conceituar e de situar a educação e o ensino não apenas em função de seus fins, mas também enfatizando sua função política e sua especificidade e, atrelada a essa questão, a necessidade das apropriações teóricas que embasam as teorias pedagógicas e decorrentes didáticas.

Assim, buscamos proporcionar aos alunos análises de diferentes conceituações de Didática em função da multidimensionalidade do processo de ensino e de aprendizagem, frente às principais contribuições da tecnologia, a partir das principais correntes do pensamento didático-pedagógico da atualidade, de onde derivam os diferentes métodos e técnicas de ensino.

Em nossas atividades com uma turma do segundo ano do curso de Pedagogia, realizamos atividade de reflexão sobre a escola, aspectos da sua história que a constituíam como escola tradicionalista e que, na atualidade, a relegam à condição de um espaço que deva ser extinto. Os argumentos para a sua extinção estão, em sua maioria, relacionados às benesses que derivaram das tecnologias, como possibilidade de educação e de ensino em consonância com a sociedade capitalista mais interconectada, centrada na racionalização de tempo, espaço e recursos econômicos e humanos.

No entanto, o dilema que se coloca, se discute e muito se teme, está relacionado à extinção de um espaço privilegiado para a apropriação de conhecimentos sistematizados e, culturalmente, constituintes da humanidade, talvez único, no enfrentamento às desigualdades sócio-econômicas postas pelas sociedades capitalistas.

Assim, para debater tais questões, realizou-se um diálogo entre o educador brasileiro Paulo Freire, formulador da Pedagogia libertadora, que se tornou expressão da educação para a emancipação dos povos oprimidos, e o matemático sul-africano Seymour Papert, considerado, segundo os autores do vídeo, "uma das maiores 
autoridades mundiais em informática na educação". Tal diálogo foi realizado na década de 1990, na Pontifícia Universidade Católica de São Paulo, e foi registrado pela TV PUC, com exclusividade.

Paulo Reglus Neves Freire, nascido em 1921 em Recife, faleceu em 1997, em São Paulo, após longos anos de militância à favor de uma transformação social por meio de homens e mulheres conscientemente livres e emancipados frente à situação de opressão posta pelas relações de dominação capitalista. Nesse sentido, vislumbrou uma educação imbricada na política. Sua crítica severa foi sobre o que denominou de “educação bancária", que corresponderia ao depósito de dogmas, porque saberes nunca serão depositados. Paulo Freire contestou a forma e conteúdo da escola tradicional, afirmando ser ela incapaz de se colocar ao lado dos oprimidos. Daí decorre a sua ideia de ser a comunidade o lócus de partida e um ponto de chegada em sua teoria, articulando, portanto, as possibilidades do ensino acontecer, necessariamente, em articulação com a cultura local de vida dos educandos, de onde, por meio de um diálogo amoroso, do que chamou de "Pedagogia do diálogo", surgiria a consciência e as condições necessárias à emancipação dos sujeitos - educador e educandos, frente a opressão sócio-econômica.

Segundo Freire, sua "Pedagogia do diálogo" tem como regra a horizontalidade das relações entre educador e educando, mediante um diálogo amoroso, que emergiria com os temas geradores originados a partir de situações vividas por ambos, na comunidade dos educandos, em busca da conscientização (arma contra a educação bancária) (SAVIANI, 1998).

Seymour Papert nasceu em Pretória, África do Sul, em 1928. Matemático e educador, trabalhou com Piaget na University of Geneva, de 1958 a 1963. Centrou suas pesquisas e ações no estudo de aspectos voltados à chamada inteligência artificial, tornando-se referência na história da Informática na Educação. Pela sua proximidade com aspectos da teoria psicogenética piagetiana, as defesas de Papert (1994) são para que os materiais favoreçam ao aluno tanto o aprender-com como o aprender-sobre-opensar, ou seja, defende que as ferramentas, sobretudo as tecnológicas, favorecem o aprender fazendo, em busca de o aluno construir aquilo que julgar significativo para ele, envolvendo-se, portanto, afetiva e cognitivamente com aquilo que está sendo produzido.

A trajetória desses dois educadores, incongruentes em certos sentidos específicos, principalmente os de origem do pensamento, apresenta, porém, traços comuns: foram homens de seu tempo e debruçaram-se sobre discussões decisivas para 
se pensar o desenvolvimento humano, como as relativas à tecnologia e seu papel na educação.

Buscamos reunir algumas dessas discussões neste artigo, a fim de também nós ofertarmos nossa contribuição para um debate e utilização da tecnologia a favor da escola e não em substituição a ela. Não significa advogarmos em favor da escola que, tradicionalmente, tem promovido as desigualdades sociais, materiais e de bens culturais e reproduzido as relações de dominação de pessoas menos favorecidas na apropriação desses bens. Mas, sim, trata-se de advogarmos em favor de uma escola que possa utilizar-se daquilo que homens e mulheres produzem para seu próprio desenvolvimento humano.

\section{Tecnologias, sociedade, educação e escola: acertos e desacertos teóricos.}

A sociedade moderna, também conhecida como sociedade da informação, é dominada pela comunicação, e sua educação, em nosso entendimento, necessita e portanto tende a extravasar as paredes da sala de aula e os muros da escola.

Essa ideia vai ao encontro das defesas tanto de Paulo Freire, quanto de Seymour Papert, segundo o diálogo no qual este texto se baseia.

Como mencionado, as defesas de Seymour Papert, em relação às possibilidades para a aprendizagem e desenvolvimento humano, via as ferramentas das tecnologias de informação e, acrescentamos, de comunicação (TICs), centralmente, os computadores, possuem como base os fundamentos da teoria psicogenética piagetiana, algumas das quais apresentamos na introdução.

Para Papert (PRIOLLI; RAMOS, 1995), via tecnologia e suas ferramentas, o professor e, em decorrência, a escola, tem como função buscar formas de se relacionar com seus alunos, desde a infância, e de "[...] pesquisar formas de se relacionar dentro do triângulo adulto, criança, saber”, o quê, na sua opinião, não tem ocorrido. Para argumentar sobre essas afirmações, Papert (PRIOLLI; RAMOS, 1995) apresenta o que considera ser os 3 estágios de desenvolvimento da criança.

O $1^{\circ}$ estágio é a do experimento, em que o bebê vai percebendo o meio em que vive através do toque, do olhar, do paladar, do olfato de forma natural. Nesse momento, a criança é super curiosa, onde esta quer brincar com tudo o que vê. Presta atenção na ação e reação dos pais. $\mathrm{O}$ auge desse aprendizado chega ao ponto em que a criança entra 
na idade escolar; o segundo estágio é a descontinuidade do aprendizado pautado nas experiências e espontaneidade da criança em aprender. Ai reside o trauma em que a criança para de aprender e deve aceitar ser ensinado. Muitas crianças estão sendo destruídas e sufocadas pelo ensino puramente tradicional, sistemático e opressivo; o terceiro estágio seria o contorno do $2^{\circ}$ estágio para o primeiro, se recusando ser oprimido ou excluído, onde o professor deva ser um mediador utilizando a tecnologia como uma das ferramentas para o aprendizado. Seria a etapa em que a criança reage contra o tradicionalismo, contra o ensino sistematizado, contra a exclusão e opressão. ${ }^{3}$

Tais estágios sistematizados por Papert (PRIOLLI; RAMOS, 1995) também vão ao encontro das ideias de teóricos de que, na sociedade moderna, a educação é um processo permanente, que não pode ser interrompido e não deve se esgotar no período de permanência do aluno na escola, mesmo que essa permanência seja altamente relevante em termos educacionais.

Segundo essa tendência de pensamento, a educação, na sociedade da informação, é também difusa: as pessoas se educam enquanto trabalham, enquanto assistem algum canal da TV ou por meio dos seus dispositivos móveis, tablets, computadores ou mesmo o rádio do seu carro, enquanto realizam as atividades normais do dia a dia, enquanto viajam, enquanto se divertem. Nesse sentido, consideram que na vida cotidiana não têm sido pontuadas essas possibilidades de articulação entre educação e trabalho e entre educação e lazer. A educação pode e deve permear todas as suas atividades, pois não deve haver limites para tal articulação.

Dessa forma, cabe-nos entender que, diferentemente do exposto no que seria o $2^{\circ}$ estágio de desenvolvimento para Papert (PRIOLLI; RAMOS, 1995), a escola que se deseja espaço privilegiado para que a educação ocorra também deve ser potencialmente pensada enquanto importante instrumento na articulação entre esses elementos. Por meio dela o ser humano pode e deve ter a possibilidade de se instruir para além do ambiente familiar. Assim sendo, sem dúvida, essas articulações constituem-se em possibilidades das pessoas apropriarem-se de conhecimentos circundantes na sociedade em que estão inseridas.

Desse modo, entendemos que o aluno só se desenvolve na experiência dialógica, assim como advoga Paulo Freire, e em espaço de acesso e permanência democráticos, em que haja oportunidades equitativas, materializadas nas vivências propostas intencionalmente pelo mediador, parceiro mais experiente. Tais proposições são

${ }^{3}$ Ideias de Papert, pinçadas do seu diálogo com Freire. 
constituídas por aspectos da cultura, em que os indivíduos reconhecem a presença do homem como sujeito histórico, principal e responsável pela existência desses aspectos e, portanto, se reconhece nesse sujeito histórico. Só adquirindo recursos próprios para sua existência como sujeito histórico, o homem adquire a consciência de que poderá agir em seu meio.

Segundo Freire (PRIOLLI; RAMOS, 1995), nem mesmo a ferramenta mais avançada superaria as possibilidades que o diálogo horizontal entre educador e educando, sobre aspectos da existência do homem em sociedade, poderia. Por isso é que a base de suas defesas é por um espaço em que esse diálogo possa acontecer e, enfim, que o homem possa identificar e compreender a sua própria historicidade, a sua própria identidade de um sujeito de compromisso com a produção de sua própria existência:

Compromisso com o mundo, que deve ser humanizado para a humanização dos homens, responsabilidade com estes, com a história. Este compromisso com a humanização do homem, que implica uma responsabilidade histórica não pode realizar-se através do palavrório, nem de nenhuma outra forma de fuga do mundo, da realidade concreta, onde se encontram os homens concretos. (FREIRE, 1985, p. 19).

Observamos que, no diálogo com Papert, Freire (PRIOLLI; RAMOS, 1995) afirma que esse espaço não precisaria chamar-se escola, mas tem que existir como lugar, tempo e direito de todos os homens que, em sociedade, precisam, equitativamente, apropriar-se daquilo que produzem.

Nessa perspectiva, Kenski (2007, p. 18) afirma que “[...] a escola também exerce o seu poder em relação aos conhecimentos e ao uso das tecnologias que farão a mediação entre professores, alunos e os conteúdos a serem aprendidos." Sobre isso, entendemos que a escola necessita pensar na redefinição dos seus objetivos, dos espaços, da organização curricular e dos seus meios didático-pedagógicos, de maneira crítica, participativa e, portanto, não seduzida por modismos ou tendências advindas com o desenvolvimento da ciência e do conhecimento.

Freire (PRIOLLI; RAMOS, 1995), no diálogo com Papert, chama, a propósito, a atenção acerca da possibilidade da adaptação em relação à aceleração tecnológica, pois, ao encontro das reflexões de Dantas $(2007$, p. 11) “[...] por trás da adaptação dos novos tempos, que exigiriam homens diferenciados, plugados às inovações tecnológicas, pode se ocultar na realidade uma acomodação latente, um sujeito inserido num marco histórico atemporal, mutável." Segundo Freire, "Quanto mais o homem é rebelde e 
indócil, tanto mais é criador, apesar de em nossa sociedade se dizer que o rebelde é um ser inadaptado." (FREIRE, 1985, p. 32).

Sobre a definição dos currículos, também Kenski (2007, p.19) ressalta que sua definição nos cursos, “[...] em todos os níveis e modalidades de ensino é uma forma de poder em relação à informação e aos conhecimentos válidos para que uma pessoa possa exercer função ativa na sociedade." Assim, a integração das tecnologias na elaboração e desenvolvimento do currículo exige uma reflexão sistemática acerca dos objetivos, de suas técnicas, dos conteúdos escolhidos, enfim, exige uma reeleitura do significado do conhecimento para uma educação que implica em transformação das pessoas e de suas condições de vida, portanto, que implica em desenvolvimento humano.

Nesse processo, a tecnologia pode ser considerada como meio potencializador da atividade dos educadores e educandos, colocando-se de forma igualmente ativa na apropriação e significação dos conteúdos escolares. As ferramentas digitais de informação e comunicação pressupõem uma mudança nas formas de relação dos educandos, educadores e gestores com a própria tecnologia, e também na própria formação do educador. Nessa medida, precisamos refletir sobre a seleção teórica do assunto, sobre o papel das tecnologias na vida pessoal e profissional do educador, etc.

\section{Escola e tecnologia: acertos éticos e práticos.}

Mediante a inserção das tecnologias na educação, educadores e educando podem trabalhar no sentido de pensar a escola como ambiente coletivo e colaborativo e, então, favorecedor às apropriações dos novos conhecimentos, dentre eles, o tecnológico, para o desenvolvimento humano.

Vale ressaltar que a ação do educador, parceiro mais experiente, perante as dificuldades de seu educando frente à utilização das ferramentas informatizadas, implica um árduo trabalho de planejamento, baseado na reflexão de todas as etapas, onde o educador age diante das indagações dos educandos, favorecendo a autonomia de novas apropriações.

Quando os educandos utilizam a tecnologia como potencializadora nos processos de apropriação do conhecimento, verifica-se que a relação educando e ferramentas tecnológicas pode proporcionar um ambiente muito peculiar em relação ao fomento da criatividade no processo de aprendizagem. 
A própria tecnologia, quando pensada como favorecedora do desenvolvimento humano, portanto, em sociedade, possui um aspecto de individualidade que implica o fortalecimento do espírito de busca pelo conhecimento do outro, que se encontra em outro espaço e tempo social de conhecimento, o que favorece, também, e sobretudo, as relações interpessoais.

Cabe ao educador, então, possibilitar que, mesmo quando o educando tem a tecnologia à disposição para suas apropriações, ele precisa ser envolvido em projetos e atividades que possam aliar o uso dessas inovações tecnológicas a um desenvolvimento, ao mesmo tempo individual e coletivo.

Nessa perspectiva, Moran (2002) considera que o educador torna-se mediador da aprendizagem, em serviço e a serviço de mediações intelectual, emocional, gerencial, comunicacional e ética. Para que isso ocorra, Moran (2002) aponta alguns princípios metodológicos norteadores da prática do educador, a saber: a integração das tecnologias às metodologias e às atividades; a integração do texto escrito, comunicação oral, escrita, hipertextual, multimídica. Ressalta a importância de o educador proporcionar aproximações das mídias das atividades, possibilitando que os educandos transitem facilmente de um meio para o outro, de um formato para o outro. Destaca, a propósito, a importância de o universo audiovisual ser trazido para as salas de aula e demais espaços da escola. Também ressalta a necessidade de que as formas práticas de trabalho docente, as técnicas e atividades de ensino, as dinâmicas propostas, bem como os processos de avaliação sejam variados, a fim de que, em algum momento, ainda que distintos, os educandos possam afetar-se pelo novo conhecimento, o que resultará em transformação e desenvolvimento dos educandos.

Segundo Moran (2002), é preciso valorizar a presença naquilo que ela tem de melhor, e a comunicação virtual, as ferramentas da tecnologia, no que ela nos favorece, ou seja, o convívio com algo ou alguém que nunca teríamos tido chance caso não fosse a existência de tais recursos. Afirma a necessidade de se buscar um equilíbrio entre os benefícios da presença e os da distância, a comunicação "olho a olho" e a virtual. Nesse último sentido, a ideia é a de o educador saber identificar e explorar a força das imagens para despertar as sensações que movem os educandos a querer saber mais. Ressalta a importância da utilização de vídeos e a escolhas de produções que afetam os educandos por todos os sentidos.

Em suas propostas para a utilização das ferramentas televisivas e do vídeo, Moran (2002, P. 39-41) destaca que o educador pode começar por vídeos mais simples, 
como sensibilização; como ilustração; como simulação; como conteúdo de ensino; como resultado de produção; integrando o processo de avaliação; vídeo-espelho. Nesse mesmo sentido, Moran (2002) ressalta algumas dinâmicas que proporcionam a realização de análises em conjunto, de aspectos gerais, funcionais, da linguagem, entre outras.

Sobre a utilização dos recursos da internet, Moran (2002) ressalta a importância de os educadores pensarem na criação de páginas e fóruns de debates, os quais facilitam a realização de pesquisas cooperativas.

Diante do exposto, impõe-se um desafio de formar educadores e estruturar ambientes para a utilização dos recursos multimídicos.

A formação inicial e continuada de professores como mediadores para essa nova realidade não tem sido privilegiada de maneira efetiva por meio das políticas públicas em educação, nem pelas universidades em seus cursos formadores e nem pelas escolas, as quais são responsáveis pela formação do professor em serviço. As soluções propostas inserem-se principalmente em programas de formação de nível de pós-graduação ou como programas de qualificação de recursos humanos. O perfil do profissional de ensino é orientado para uma determinada "especialização", e, como resultado, evidencia-se a fragilidade das ações e da formação, refletidas também por intermédio dos interesses econômicos e políticos.

Com essas tecnologias, são exigidas novas formas de aprender, novas competências; são necessárias novas formas de se realizar o trabalho pedagógico e, fundamentalmente, se faz necessário formar continuamente o educador para atuar neste ambiente telemático.

Nas discussões sobre a formação de professores como mediadores, tanto inicial quanto continuada, o impacto e o uso apropriado das tecnologias digitais de informação e comunicação têm fomentado muitas pesquisas, seminários, simpósios, etc.

Nos últimos anos, muitos grupos de pesquisa têm dedicado suas atividades aos impactos das tecnologias digitais de informação e comunicação sobre a formação docente. Não podemos falar sobre esse impacto sem destacar as questões relacionadas à formação inicial do docente, sobre a identidade do profissional da docência, as características curriculares dos cursos de formação, etc.

Por isso, identificamos aqui que, ao pensarmos o currículo em relação à formação de educadores, temos que levar em consideração as forças sociais que alicerçam a construção curricular, as relações de poder que interferem nas políticas 
públicas para o ensino superior brasileiro, as discussões emergentes em relação às bases epistemológicas da construção da identidade do profissional da educação, etc.

Remetendo-nos a essas inferências, constatamos que a construção do currículo de formação de educadores sofre com diversas intervenções governamentais, sem muitas vezes sequer passar por estudos aprofundados sobre suas problemáticas, deixando lacunas em algumas áreas atualmente essenciais, como o uso das tecnologias digitais de informação e comunicação na formação inicial. Contudo, muitos projetos atuais de reconfiguração curricular para a formação do educador têm levado em consideração essas questões, dando-nos esperança para alcançarmos uma base sólida de reflexão.

Nesse sentido, entendemos que esses saberes anteriormente descritos são marcados por constantes transformações em meio às mudanças nas concepções pedagógicas e também sobre os processos educacionais.

Em relação às competências, muitos teóricos defendem que é uma categoria relacionada à identidade política e técnica do profissional, conquistada em sua formação inicial, garantindo-lhe um domínio sobre sua profissão.

Essas competências dizem respeito não somente aos saberes docentes específicos constituídos em cada formação, mas também aos saberes que se constituem na prática. Sobre isso afirma Tardiff (2002, p. 119):

\footnotetext{
O trabalho dos professores de profissão seja considerado como um espaço prático específico de produção, de conhecimentos e de saberfazer específicos ao ofício de professor. Essa perspectiva equivale a fazer do professor - tal como o professor universitário ou o pesquisador da educação - um sujeito do conhecimento, um ator que se desenvolve e possui sempre teorias, conhecimentos e saberes de sua própria ação.
}

Não consideramos apenas a docência no campo das práticas educativas; o uso das tecnologias digitais de informação e comunicação envolve outros aspectos do processo de ensino e aprendizagem, como o currículo escolar, a avaliação da aprendizagem, metodologias de ensino, etc.

Ao falar de todos esses aspectos da prática educativa, precisamos considerar o fato de que as inovações tecnológicas têm transformado a vida das pessoas como um todo. Não obstante, na educação e na escola, enfrentamos novos desafios e novas perspectivas sobre o conhecimento e o processo de aprendizagem. A esse respeito, vejamos o que diz Marinho (2002, p. 46): 


\begin{abstract}
A escola, principalmente por meio do professor, não mais detém o monopólio do conhecimento e tem de assumir esse fato. Por isso é necessário pensar no computador como um agente essencial para trazer, para o espaço da aprendizagem, a informação e o conhecimento que agora estão disponíveis de forma imediata, na ponta dos dedos pausados sobre um teclado.
\end{abstract}

Torna-se importante salientar que pesquisadores das Ciências Humanas, professores e profissionais da educação podem utilizar esses parâmetros no auxílio às suas práticas ou suas pesquisas, no intuito de agregar elementos importantes às suas reflexões e até mesmo às suas práticas educativas.

\title{
Considerações finais
}

Contemporâneos que tentamos nos tornar do uso e discussões sobre as tecnologias e suas ferramentas na educação, sempre nos colocamos como desafio as reflexões acerca das possibilidades de sua utilização nos processos de ensino e de aprendizagem em que participamos, sobretudo nos processos de formação inicial dos nossos alunos no curso de Pedagogia em que atuamos, em uma universidade estadual paulista. Também colocamo-nos tais desafios em atividades de ensino nos cursos de pós-graduações em que atuamos, tanto na área da saúde quanto da educação. Ressaltamos, ainda, que igualmente colocamo-nos tal desafio para a realização de nossas atividades extensionistas na formação de professores em formação continuada nas escolas.

Em Didática, especificamente nas disciplinas de Didática que integram a grade curricular do Curso de Pedagogia da Universidade na qual somos docentes, buscamos enfatizar discussões que consideramos de fundo filosófico, como as trazidas sobretudo por Paulo Freire em seu diálogo com Seymour Papert. O nosso objetivo com tais discussões é o de superarmos as superficialidades das discussões, em favor da mobilização dos futuros docentes para a ação-reflexão-ação acerca dos fenômenos educativos que acontecem na sociedade, dentre os quais os do papel da tecnologia frente à educação, à escola e ao ensino que defendemos.

Nesse sentido, buscamos sempre as suas múltiplas concordâncias e dissonâncias nas fundamentações teóricas que cercam tais fenômenos, com rigor e objetividade, o 
que acreditamos poder ser possível apenas à luz de uma concepção de educação e de escola capaz de pensar todos os fenômenos que a envolvem em termos de possibilidades para o desenvolvimento humano em sociedade.

Também, nossa função de educadores e formadores de outros educadores nos move a pensar em propostas pedagógicas, naquilo que denominamos de possíveis acertos éticos e práticos, trazidos por pesquisadores que se debruçaram sobre a questão do uso da tecnologia na escola, não a fim de substituí-la, mais sim de potencializá-la como espaço, tempo e direito à apropriação do conhecimento para o desenvolvimento humano. Nesse sentido, ressaltamos uma preocupação central com relação aos nossos alunos em formação docente inicial, que é aquela que se faz na própria universidade.

Todo o exposto embasou as nossas críticas ao uso das inovações na educação, dentre as quais os das ferramentas tecnológicas que, muitas vezes, não têm considerado a urgência do fortalecimento das relações humanas, sobretudo em nossa sociedade capitalista, em que os processos não favorecem um pensar sobre as atividades que realizamos e os bens que produzimos para nosso desenvolvimento. No caso das tecnologias, importante resultado do avanço tecnológico para a educação, em muitos casos, se tornam simples instrumentos de instrução e, então, poderoso instrumento de produção de desigualdades na luta pela apropriação do conhecimento.

Sendo assim, os recursos da tecnologia são potencialmente favorecedores para que os educandos possam desenvolver, na escola, vínculos que lhes possibilitem compreender e situar o seu universo particular com o do outro, para que possam agir na sociedade de forma consciente e de maneira colarativa. $\mathrm{O}$ trabalho com essas inovações pressupõe um árduo empenho em articular a reflexão sobre as propostas dos ambientes de aprendizagem estruturadas nas tecnologias digitais de informação e comunicação e a formação e desenvolvimento humano.

O propósito de introduzir novas tecnologias na escola é pensá-la como ambiente único e propício para realizar ações novas, social e pedagogicamente importantes, que não se poderiam realizar de outras maneiras. O educando, utilizando metodologias adequadas, poderá utilizar essas tecnologias na integração de disciplinas estanques. A escola passa a ser um lugar singular, que não apenas prepararia o educando para a vida, mas ofereceria condições para que ele pudesse viver intensamente em ambiente propício e prenhe de possibilidades.

Às escolas cabe a incorporação das tecnologias digitais de informação e comunicação e a condução do processo de mudança na atuação do educador, que é o 
principal gestor dessas transformações. Ele passa a ser o mediador e deverá preparar o educando para buscar, da maneira mais acertada possível, a informação em fontes de diversos tipos. É necessário também propor condições para que a comunidade escolar se conscientize da importância dessas tecnologias para o seu desenvolvimento social e cultural.

Como ressaltamos, a questão da qualidade da aprendizagem dos educandos, utilizando as tecnologias, poderá se dar na forma de trabalho com o currículo e por meio da ação do educador, além da promoção do incentivo à utilização de suportes tecnológicos de ensino, estimulando pesquisas interdisciplinares necessárias a análises de aspectos da realidade nacional. Os mais avançados suportes tecnológicos poderão ser empregados para criar, experimentar e avaliar aplicativos educacionais, cujo alvo é avançar um novo paradigma na educação, adequado à sociedade em que vivemos, para redimensionar os valores humanos, aprofundar as habilidades de pensamento e tornar o trabalho entre educadores e educandos mais participativo, motivador e humanizante.

Como afirmam os teóricos, alguns dos quais nos valemos neste artigo, somente podemos educar para a autonomia, para a liberdade, em processos participativos, interativos, libertadores, que respeitem as diferenças, que incentivem, apoiem, orientem.

Nesse sentido, e como afirma Moran (2002), precisamos de educadores maduros intelectual e emocionalmente, pessoas entusiasmadas, abertas, que saibam motivar e dialogar com os educandos, com outras pessoas da comunidade escolar e com os avanços do conhecimento, dentre os quais os tecnológicos. Entretanto, não nos esqueçamos que também influenciam e determinam tal cenário as possibilidades da ação de administradores, diretores e coordenadores dispostos às mudanças.

Enfim, e como resultados de nossas reflexões, ressaltamos que, quando a função política e especificidade da educação e do ensino são recuperadas pelo educador, fundamentadas em uma ideia de educação e ensino para o desenvolvimento humano, a importância da escola se amplia diante da necessidade e das possibilidades de ela se constituir em tempo, espaço e direito de os educandos poderem valer-se também dos avanços tecnológicos para a apropriação do conhecimento produzido pela humanidade da qual eles fazem parte. 


\section{REFERÊNCIAS}

DANTAS, Jéferson Silveira. Perspectivas educacionais no pensamento de Anísio Teixeira e Paulo Freire. PerCursos, Florianópolis, v. 8, n. 2, p. 03-18, jul./dez. 2007.

FREIRE, Paulo. Educação e Mudança. Trad.: Moacir Gadotti e Lilian Lopes Martins. 10. ed. Rio e Janeiro: Paz e Terra, 1985.

KENSKI, Vani Moreira. Educação e tecnologias: o novo ritmo da informação. Campinas: Papirus, 2007.

MARINHO, Simão Pedro. Tecnologia, educação contemporânea e desafios ao professor. In: Joly, Maria Cristina R. Azevedo (org). A tecnologia no ensino: implicações para a aprendizagem. São Paulo: Casa do Psicólogo, 2002.

MORAN, José Manuel. Ensino e aprendizagem inovadores com tecnologias audiovisuais e telemáticas. In MORAN, José Manuel, MASETTO, Marcos Tadeu., BEHRENS, Maria Aparecida. Novas tecnologias e mediação pedagógica. 5. ed. Campinas, SP, Papirus, p. 11-65, 2002.

PRIOLLI, Gabriel; RAMOS, Eduardo. Seymour Papert e Paulo Freire: uma conversa sobre informática, ensino e aprendizagem. São Paulo: TV PUC-SP, nov. 1995. (Série de vídeos: O Futuro da Escola - Obra de Paulo Freire). Disponível em: <http://acervo.paulofreire.org:80/xmlui/handle/7891/395>. Acesso em 04 abri. 2011.

SAVIANI, Dermeval. História das idéias pedagógicas no Brasil. 2. ed. e ampl. Campinas - SP: Autores Associados, 2008. - (Coleção Memória da Educação).

TARDIFF, Maurice. Os professores enquanto sujeitos do conhecimento: subjetividade, prática, e saberes no magistério. In: CANDAU, Vera Maria (Org). Didática, currículo e saberes escolares. 2. ed. Rio de Janeiro: DP\&A Editora, 2002.

\section{Como referenciar este artigo}

CASTRO, Rosane Michelli de.; LANZI, Lucirene Andrea Catini. O futuro da escola e as tecnologias: alguns aspectos à luz do diálogo entre Paulo Freire e Seymour Papert. Revista Ibero-Americana de Estudos em Educação, Araraquara, v. 12, n. esp. 2, p. 1496-1510, ago./2017. Disponível em: <http://dx.doi.org/10.21723/riaee.v12.n.esp.2.10305>. E-ISSN: 1982-5587.

Submetido em: 08/06/2017

Aprovação final em: 20/08/2017 